\title{
Helicos single molecule sequencing: unique capabilities and importance for molecular diagnostics
}

Patrice M Milos

From Beyond the Genome: The true gene count, human evolution and disease genomics

Boston, MA, USA. 11-13 October 2010

\section{Background}

Helicos Single Molecule Sequencing provides a unique view of genome biology through direct sequencing of cellular nucleic acids in an unbiased manner, providing both quantitative and accurate sequence information. The simple sample preparation involves no ligation or PCR amplification, allowing direct sequencing of targeted DNA or RNA molecules. DNA and RNA can be directly hybridized to the flow cell, eliminating many intermediary steps that can introduce sample loss or bias. From these methods, a diverse array of applications have been successfully demonstrated on the HeliScope Sequencer. For example, human genome sequencing for accurate variant detection; multiplexing of DNA for targeted resequencing; copy number variation studies from both fresh tumor tissue and formalin-fixed paraffin-embedded tissue samples; RNA-seq studies demonstrating the unexplored biology that exists in the transcriptome; small RNA studies leading to the identification of new classes of RNAs [1]; and the direct capture and sequencing of nucleic acid from as few as 400 cells with the end goal of single cell measurements [2]. Current efforts now focus on applying these unique attributes to develop novel substrate for molecular diagnostic tests.

\section{Ongoing programs}

Recent studies identified the attributes of the Helicos Single Molecule Sequencing technology that provide unique features for molecular diagnostic application including combining the simplicity of sample preparation with sequencing, the scalability of the workflow and the quantitative power of the sequencing. Initially, Helicos is developing a molecular diagnostic test that will

Helicos BioSciences Corporation, Cambridge, MA 02139, USA identify gene mutations indicative of a woman's increased risk of developing hereditary breast or ovarian cancer. We are also investigating longer-term studies to examine the quantitative capabilities of our core technology in order to develop molecular diagnostic tests based on the detection and quantification of foreign DNA/RNA circulating in the bloodstream, such as a non-invasive prenatal diagnostic test.

\section{Acknowledgements}

The work presented represents the collective, dedicated contributions of numerous Helicos scientists and collaborators.

Published: 11 October 2010

\section{References}

1. Kapranov $P$, et al: New class of gene-termini-associated human RNAs suggests a novel RNA copying mechanism. Nature 2010, 466:642-646.

2. Ozsolak F, et al: Amplification-free Digital Gene Expression Profiling from Minute Cell Quantities. Nature Methods 2010, 7:619-621.

doi:10.1186/gb-2010-11-S1-I14

Cite this article as: Milos: Helicos single molecule sequencing: unique capabilities and importance for molecular diagnostics. Genome Biology 2010 11(Suppl 1):114.

Submit your next manuscript to BioMed Central and take full advantage of:

- Convenient online submission

- Thorough peer review

- No space constraints or color figure charges

- Immediate publication on acceptance

- Inclusion in PubMed, CAS, Scopus and Google Scholar

- Research which is freely available for redistribution 